\title{
Lower Lip
}

National Cancer Institute

\section{Source}

National Cancer Institute. Lower Lip. NCI Thesaurus. Code C94572.

The lip that covers the anterior portion of the mandible. 